\title{
Energy-Saving Effect of a Hybrid Air-Conditioning System Using Natural Ventilation in an Office Building
}

\author{
Tomoya Sakamoto and Yasuyuki Shiraishi
}

\begin{abstract}
The energy-saving effect of a hybrid A/C system during operation phase in springtime was shown quantitatively based on field measurements and numerical simulations. A numerical model of the natural ventilation rate for a building with flow control inlets and outlets was proposed in this study by means of a thermal and air flow network analysis. The prediction accuracy of this model was also verified by performing a comparison with field measurements of a hybrid $\mathrm{A} / \mathrm{C}$ system in an existing office building. Power consumption for $\mathrm{A} / \mathrm{C}$ was reduced by about $20 \%$ on each floor by introducing natural ventilation, and predicted energy savings for the system was about $22.3 \%$ on average.
\end{abstract}

Index Terms-Natural ventilation, flow control, field measurement, thermal and airflow network analysis.

\section{INTRODUCTION}

The internal heat load of office buildings in Japan has increased due to the rapid automation of offices. Accordingly, the use of active air-conditioning $(\mathrm{A} / \mathrm{C})$ systems to maintain indoor thermal comfort in offices has also increased. To realize a sustainable society, however, the reduction of cooling loads (especially internal heat loads) by the effective use of outdoor air has been attempted. Recently, A/C systems that combine natural ventilation with artificial cooling ("hybrid A/C systems" hereinafter) have received increased attention [1]. These hybrid $\mathrm{A} / \mathrm{C}$ systems are considered an effective means of utilizing natural resources, and many office buildings are adopting such systems. For efficient introduction of outdoor air into buildings, flow control has been installed at ventilation inlets and outlets. Although hybrid $\mathrm{A} / \mathrm{C}$ systems are expected to decrease energy consumption when cooling, the quantitative effect of a system is influenced by the building shape, site environment, weather conditions and other factors. Therefore, the estimations of natural ventilation rates and energy-saving effects of hybrid $\mathrm{A} / \mathrm{C}$ systems have been difficult. Due to the significance of hybrid $\mathrm{A} / \mathrm{C}$ systems, numerous research studies have been performed (e.g. [2], [3]), however little is known about the quantitative characteristics of these systems especially with flow control inlets and outlets.

The aim of this study is to use actual measurements and numerical simulation to quantitatively measure natural ventilation and energy-saving effects of spring (interim season) operation of a hybrid $\mathrm{A} / \mathrm{C}$ system installed in an office building with flow control inlets and outlets in the city of Kitakyushu, Fukuoka, Japan.

Manuscript received June 18, 2013; revised July 25, 2013.

The authors are with The University of Kitakyushu, Japan (e-mail: t2mbb015@eng.kitakyu-u.ac.jp; shiraishi@kitakyu-u.ac.jp).

\section{BUILDING SPECIFICATIONS}

The building exterior, the north-south vertical cross section illustrating the natural ventilation routes and a typical floor and ceiling plan of this building are shown in Figs. 1-3, respectively. This building is located in the city of Kitakyushu in Fukuoka, Japan. The curtain wall of double glazing glass with low emissivity (thermal transmittance: 2.6 $\mathrm{W} / \mathrm{m}^{2} \mathrm{~K}$, solar absorptivity: 0.3 , solar transmittance: 0.4 ) constitutes the north and south sides of the work space of each story. The cooling set-point temperature of each story is usually set as 26-27 degrees C. Building energy management system (BEMS) is installed throughout the building, which uses various sensors inside and outside of the building, in order to measure the energy consumption etc. or to automatically control equipments and openings. Outdoor air is introduced into the building through inlets installed in the north and south sides of each story, as shown in Fig. 3 and 4. This air then passes through the stairwell before being exhausted from outlets installed in the monitor roof of the building.

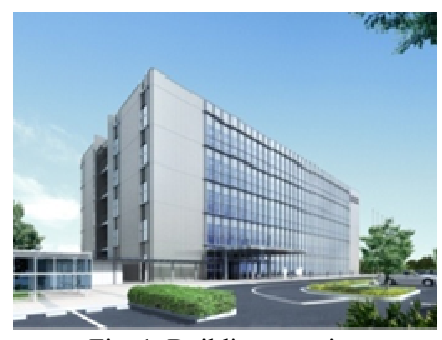

Fig. 1. Building exterior

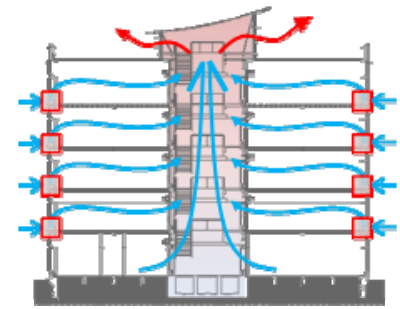

Fig. 2. North-south vertical cross section

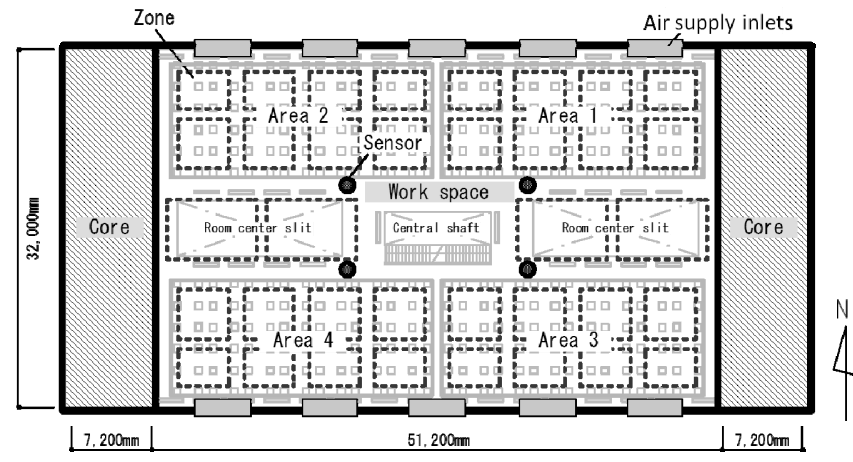

Fig. 3. Floor plan of standard floor 
Each inlet has P-Q characteristics, and so excessive inflow of outdoor air can be restricted by automatically controlling the inlet valve according to the pressure difference between the interior and exterior of the building. Each outlet has backflow control characteristics such that, if the pressure difference becomes negative, backflow is prevented by closing the outlet. Furthermore, all inlets and outlets in the building are automatically controlled by BEMS, which judges whether natural ventilation should be performed based on a number of conditions (Table II).

TABLE I: NATURAL VENTILATION ON/OFF MODE

\begin{tabular}{l|l|l|l|l|l}
\hline Natural Ventilation ON & Inlets & Outlets & Mechanical ventilation & Heat exhaust fan & Notes \\
\hline A. Natural supply/exhaust mode & Open & Open & OFF & OFF & \\
\hline B. Mechanical exhaust mode & Open & Closed & OFF & ON & During rain \\
\hline C. Mechanical supply/exhaust mode & Closed & Closed & ON & OFF & During strong winds \\
\hline Natural Ventilation OFF & Inlets & Outlets & Mechanical ventilation & Heat exhaust fan & Notes \\
\hline D. Normal A/C mode & Closed & Closed & ON & OFF & Total heat Exchanger \\
\hline
\end{tabular}

Three natural ventilation $\mathrm{ON}$ modes, A-C in Table I, control air inlets, air outlets, mechanical air supply and exhaust, and heat exhaust, according to changes in outdoor conditions, such as rain and strong winds. Natural ventilation OFF mode ( $\mathrm{D}$, normal $\mathrm{A} / \mathrm{C}$ mode in Table I) enables fully mechanical ventilation via a total heat exchanger. Switching to one of the natural ventilation $\mathrm{ON}$ modes requires fulfillment of the conditions listed in Table II. A package air-conditioning (PAC) unit is installed above the ceiling, near the centre of the room, causing air to circulate through a slit in the ceiling (Fig. 4). Mechanical ventilation is performed in a similar manner to $\mathrm{A} / \mathrm{C}$, with air supplied from inlets and expelled outside the building via ducts from special-purpose outlets installed above the ceiling.

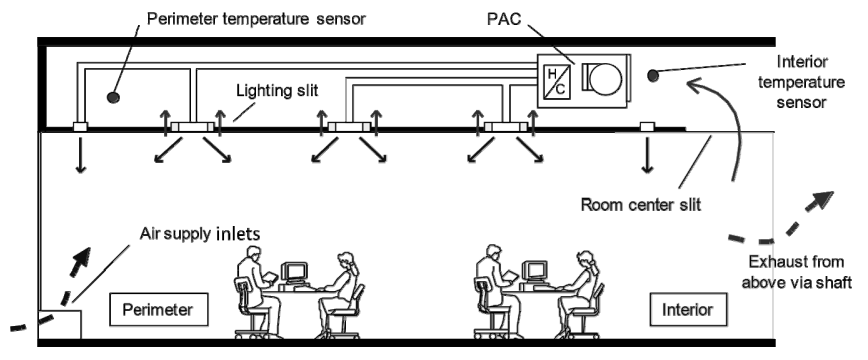

Fig. 4. Conceptual diagram of a hybrid $\mathrm{A} / \mathrm{C}$ system

TABLE II: CONDITIONS OF THE MEASUREMENTS

\begin{tabular}{l|l}
\hline 1) Enthalpy & Outdoor air enthalpy $<$ Indoor air enthalpy \\
\hline 2) Outdoor temperature & $\begin{array}{l}\text { Lower limit }<\text { Outdoor air temperature }< \\
\text { Upper limit }\end{array}$ \\
\hline $\begin{array}{l}\text { 3) Dew point } \\
\text { temperature }\end{array}$ & $\begin{array}{l}\text { Lower limit }<\text { Outdoor dew point temperature } \\
<\text { Upper limit }\end{array}$ \\
\hline 4) Indoor temperature & Setting value $-\alpha^{\circ} \mathrm{C}<$ Indoor air temperature \\
\hline
\end{tabular}

\section{OVERVIEW OF THE MEASUREMENTS}

Measurements were performed between May 1 and May 31, 2012, which is spring in Japan. Table III shows the measurement items recorded. Measurements primarily used BEMS based measurement data, and indicate natural ventilation properties during the measurement period in accordance with weather and other related conditions, as well as air inlet open/close state and wind speed. Obtaining information related to natural ventilation properties alongside internal load and cooling load allows for a detailed understanding of the operational status within a given building.

TABLE III: MEASUREMENT ITEMS

\begin{tabular}{|c|c|c|}
\hline \multicolumn{2}{|r|}{ Measurement items } & Measurement methods and \\
\hline \multirow{7}{*}{ 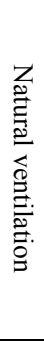 } & Outdoor wind direction and speed & $\begin{array}{l}\text { Japan Meteorological } \\
\text { Agency (Yahata) [4] }\end{array}$ \\
\hline & Outdoor air temperature & \multirow{6}{*}{ BEMS data } \\
\hline & Outdoor dew point temperature & \\
\hline & Outdoor and indoor air enthalpy & \\
\hline & Indoor air temperature and setting & \\
\hline & Opening-closing condition of inlets & \\
\hline & Wind speed at inlets & \\
\hline \multirow{4}{*}{$\begin{array}{l}\stackrel{T}{8} \\
\stackrel{0}{0} \\
\stackrel{0}{0} \\
\stackrel{0}{0}\end{array}$} & $\begin{array}{l}\text { Indoor solar radiation (north and } \\
\text { south side vertical plane) }\end{array}$ & $\begin{array}{l}\text { ML-020VM / EKO } \\
\text { Instruments }\end{array}$ \\
\hline & $\begin{array}{l}\text { Power consumption at electrical } \\
\text { outlets }\end{array}$ & \multirow{3}{*}{ BEMS data } \\
\hline & Power consumption of $\mathrm{A} / \mathrm{C}$ systems & \\
\hline & Heat load of $\mathrm{A} / \mathrm{C}$ system & \\
\hline \multirow{2}{*}{ 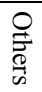 } & Return air temperature at $\mathrm{A} / \mathrm{C}$ systems & \multirow{2}{*}{ BEMS data } \\
\hline & $\mathrm{CO}_{2}$ concentration & \\
\hline
\end{tabular}

\section{MEASUREMENT RESUlts}

\section{A. Outdoor Weather}

Figs. 5-8 show timelines of various weather conditions (outdoor air temperature, outdoor dew point temperature, solar radiation, and outdoor wind speed) during the measurement period. Values indicated are moving averages over 10 min periods, with the exception of "solar radiation," which indicates cumulative values as measured at north and south vertical planes from the third floor interior. Focusing on outdoor temperature, measurements were generally within the initial range for implementation of natural ventilation $\left(16.0-26.0^{\circ} \mathrm{C}\right)$, but the lower limit was raised in the first half of the measurement period (May 11), resulting in a period where values were below the minimum. Outdoor dew point temperatures exceeded the upper limit condition somewhat frequently, particularly during the second half of the measurement period. There were four days (Fig.7) of rain during the period, and Figs. 5 and 6 show that there were many days of high humidity. Average outdoor wind speed (Fig.8) was fairly strong, exceeding $6 \mathrm{~m} / \mathrm{s}$ during the first half 
of the measurement period, but the average for the entire period was only $2.2 \mathrm{~m} / \mathrm{s}$. Northern and southern winds prevailed during the entire measurement period.

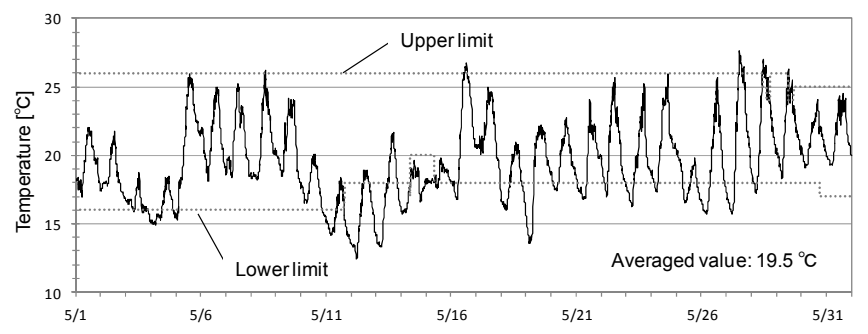

Fig. 5. Outdoor air temperature

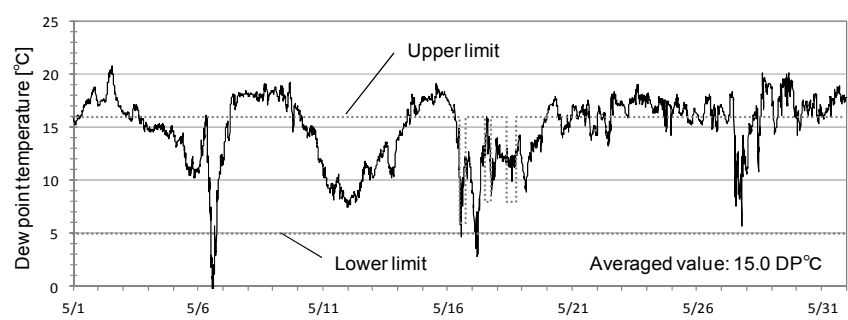

Fig. 6. Outdoor dew point temperature

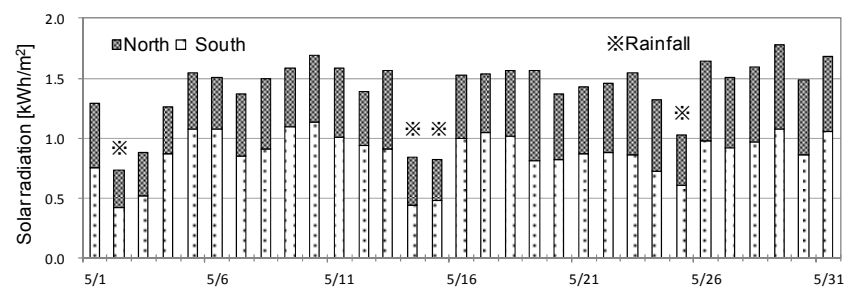

Fig. 7. Solar radiation at indoor vertical plane

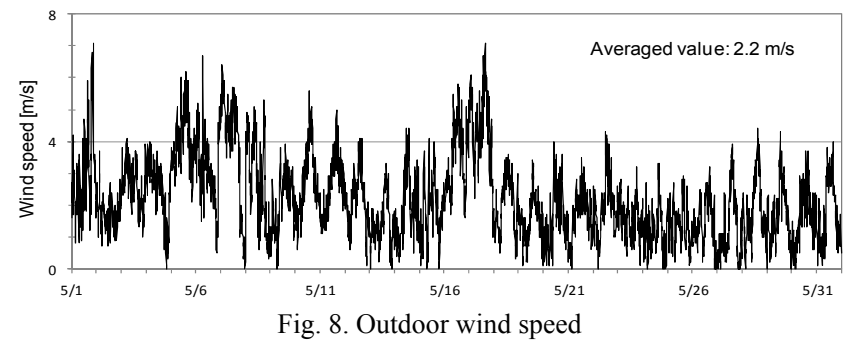

\section{B. Air Supply from Inlets}

The total time of natural ventilation (times when at least one air supply inlet was open) was $191.0 \mathrm{~h}(25.7 \%)$. Approximately $69.6 \%$ of that time was night purge periods, for $58.0 \mathrm{~h}$ of cooling and $133.0 \mathrm{~h}$ of night purging.

Fig. 9 shows air supply volumes per inlet by floor and area. There are no extreme differences between values, and the airflow control features kept maximum airflow below 1400 $\mathrm{m}^{3} / \mathrm{h}$. The average air supply volume for all inlets was 437 $\mathrm{m}^{3} / \mathrm{h}$, and $13984 \mathrm{~m}^{3} / \mathrm{h}$ per floor. This is approximately double the amount of air exchange required by the Japanese Building Standards Law $\left(6554 \mathrm{~m}^{3} / \mathrm{h}\right.$ per floor, [6]).

\section{Equipment Usage Conditions}

Fig. 10 shows cumulative daily values for the internal load (electric power consumption of office automations $(\mathrm{OA})$ and lighting equipments) and cooling load of floors 2-5, and indicates a connection between their behaviors. Note that on May 10, 11, and 14 the cooling load was lower than the internal load, likely due to low outdoor temperatures that resulted in efficient handling of internal load by natural ventilation.

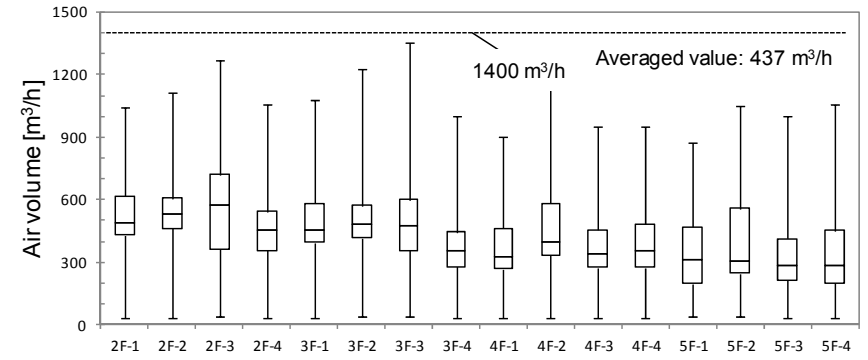

Fig. 9. Air supply volumes per inlet by floor and area

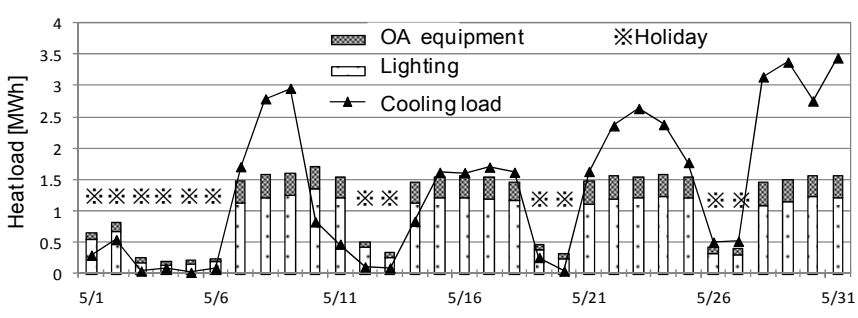

Fig. 10. Internal load and cooling load of floors 2-5

\section{Verification of Energy Savings on Representative Days}

Fig. 11 shows the outdoor temperature, ventilation rate for the 4th floor, heat load (internal load and solar radiation), and cooling load for the representative days of May 10 and 15. May 10 is the day in which natural ventilation was performed to the greatest extent, while no natural ventilation occurred on May 15 because of that day's high humidity and dew point temperature above the upper limit (Fig. 6). Comparing these two days, we see that May 10 had an overall higher heat load, but cooling load was higher on May 15 (178.9 kWh on May 10 versus $372.7 \mathrm{kWh}$ on May 15). This suggests that natural ventilation may have led to a reduction of heat load, but such a statement cannot be made with certainty because numerous other factors influence cooling load, including temperature, humidity, heat load and its unevenness, and temperature settings, and furthermore various conditions differed between the two days. It is thus necessary to investigate these matters under similar conditions through numerical simulations.

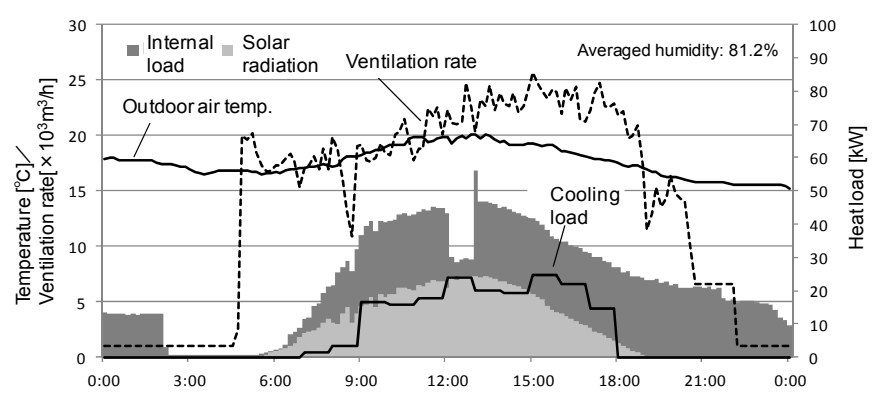

1) May 10 (Natural ventilation)

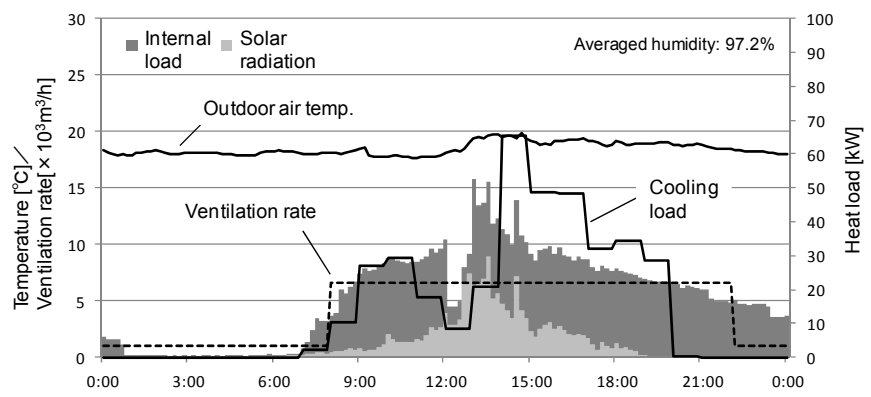

2) May 15 (Mechanical ventilation)

Fig. 11. Outdoor temperature, ventilation rate, heat load, and cooling load for the representative days 


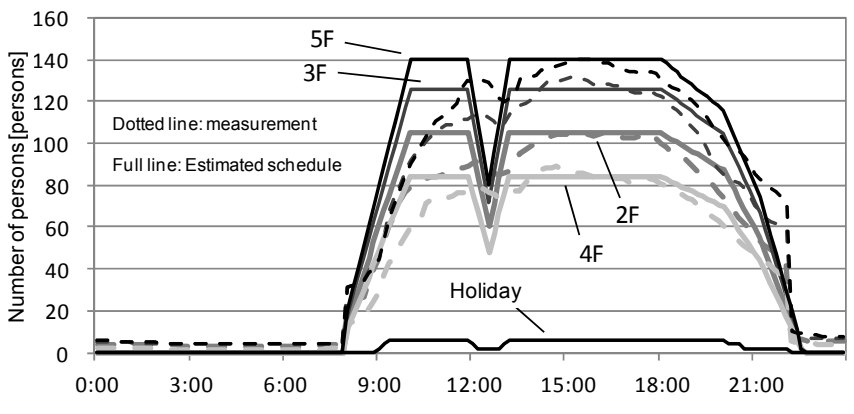

Fig. 12. Estimated number of persons per weekday and holiday

\section{OVERVIEW OF THE ANALYSIS}

A computer program NETS for the practical simulation of coupled building heat, gas and air transfer system [5], based on the thermal and air flow network analysis, was adopted. NETS can simulate the feedback or the schedule control on models' structural changes and various driving condition changes. The analysis of seasonal (spring) operation in the target building was performed using a previously created analysis model [6] and by 1) switching ventilation modes according to conditions for natural ventilation, and 2) implementing heating schedules. Table IV shows the analysis conditions. Prior to this analysis, wind pressure coefficients at all inlets and outlets were calculated in 16 wind directions based on the results of an outdoor CFD (Computational Fluid Dynamics) analysis that considered the surrounding buildings [6]. The prediction accuracy of the network analysis was thus improved by using these coefficients.

Table $\mathrm{V}$ also shows a case analysis according to this report. As the standard case (Case A), it has been performed analysis for a hybrid $\mathrm{A} / \mathrm{C}$ system under the ideal operating conditions according to Table II in the same building. There were the following difficulties during actual measurements that the prohibition of natural ventilation by office workers closing ventilation inlets at each area, so a second case (Case B) that duplicates the problem was analysed, and measured values were compared with those in the model to confirm its accuracy. To represent energy savings quantitatively, a third case (Case C) was analysed, in which no natural ventilation (only mechanical ventilation) was performed, and those values were compared with the measured ones.

TABLE IV: ANALYSIS CONDITIONS OF THERMAL AND AIR FLOW NETWORK ANALYSIS

\begin{tabular}{l|l}
\hline \hline Calculation period & $2012 / 5 / 1 \sim 5 / 31$ (Measurement period) \\
\hline Calculation domain & Work spaces of floors $2-5$ \\
\hline Meteorological data & $\begin{array}{l}\text { Outdoor air temperature and humidity: BEMS data } \\
\text { Outdoor wind speed and direction: Japan Meteorological Agency (Yahata) [4] }\end{array}$ \\
\hline A/C period & Weekday: $8: 00 \sim 22: 00$ \\
\hline Air supply volumes of mechanical ventilation (1 floor) & $\begin{array}{l}\text { A/C period: } 6600 \mathrm{~m}^{3} / \mathrm{h} \\
\text { Night purge period: } 1000 \mathrm{~m}^{3} / \mathrm{h}\end{array}$ \\
\hline Heat load & $\begin{array}{l}\text { Office automations }(\mathrm{OA}) \text { and lighting equipments, solar radiation: Figs.7,10 } \\
\text { Human body: Fig.12 }\end{array}$ \\
\hline Nodal points (Thermal network) & 291 points \\
\hline Flow paths (Airflow network) & 75 flow paths \\
\hline Calculation interval & 10 min (unsteady) \\
\hline \hline
\end{tabular}

TABLE V: CASE ANALYSIS

\begin{tabular}{|c|c|c|c|c|c|}
\hline \multirow{2}{*}{ Case No. } & \multirow{2}{*}{ Description of each case } & \multirow{2}{*}{ Purpose of analysis } & \multirow{2}{*}{ Natural ventilation } & \multicolumn{2}{|c|}{ Flow control } \\
\hline & & & & Inlets & Outlets \\
\hline Case A & Ideal operating conditions & - & o & o & o \\
\hline Case B & Recreation of the difficulties by office workers & Validation of prediction accuracy & o & o & o \\
\hline Case C & Only mechanical ventilation & Estimation of energy-saving effect & $x$ & 0 & 0 \\
\hline
\end{tabular}

\section{A. Ventilation Mode Switching by Natural Ventilation Conditions}

The feedback control to switch ventilation networks [6] was used, thus recreating the natural/mechanical ventilation mode switches according to the conditions for natural ventilation control listed in Tables I and II.

\section{B. Flow Control at Inlets and Outlets}

P-Q characteristics of inlets were reproduced in the analysis by changing between two types of ventilation network [6], where the pressure loss coefficient and exponential differed according to the difference between the outdoor and indoor pressures. Backflow control at the outlets was also reproduced by using a feedback control technique [6]. Specifically, if the difference between the outdoor and indoor pressure at each outlet became negative, the area of the outlet was set to $0 \mathrm{~m}^{2}$.

\section{Heating Schedule}

$\mathrm{CO}_{2}$ concentration and ventilation data (from periods when only mechanical ventilation was performed) were applied to the Seidel formula in order to create persons number schedules for heating schedules from human bodies. Fig. 12 shows the estimated number of persons per weekday and holiday as average daily fluctuations. Because there were differences by floor, the schedule was divided and created by floor based on differences in the actual number of persons present and $\mathrm{CO}_{2}$ concentration by time difference, as well as based on the existing literature [7].

\section{ANALysis RESUlts}

\section{A. Ventilation of Prediction Accuracy}

Fig. 13 and Fig. 14 show cumulative values for natural 
ventilation time and inlet airflow volume by floor and area (Fig.3). The results for both Case A and Case B are given as analysis values. Comparing the measured values and those of Case B (recreation of the difficulties), it has been found that zone $5 \mathrm{~F}-4$ had the largest error, with the time of natural ventilation being $18.1 \%$ (approximately $32 \mathrm{~h}$ ) shorter in Case $\mathrm{B}$ than in actual measurements. One possible cause is a temperature increase due to an unscheduled increase in the number of persons present, for example, due to workers doing overtime, which would raise indoor temperatures and thus lengthen the period for which conditions were met. Another possible cause is variability in the indoor thermal environment caused by unevenness of internal load or the thermal stratification. Otherwise, however, both sets of values largely agree, with an average error of only $2.7 \%$. Conversely, comparing measured values in Fig. 13 with those of Case A (ideal operating conditions) shows that analysis values exceed measured values in many cases, with an average $28.3 \%$ increase.

Actual and analysis (Case B) values also largely agree in Fig. 14, with an average error of $9.8 \%$. While there are some areas with significant error (62.4\% in $5 \mathrm{~F}-1$, for example), it can be presumed that results are sufficiently precise to capture the overall behaviour of the examined building.

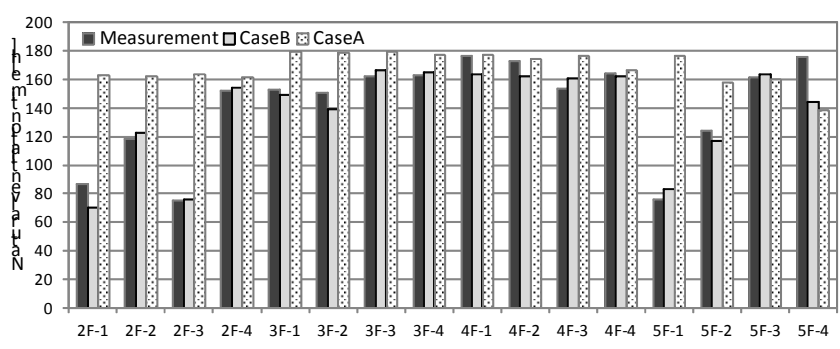

Fig. 13. Cumulative values for natural ventilation time

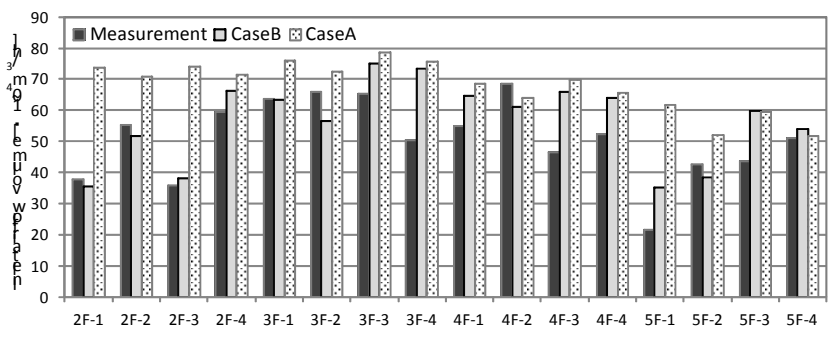

Fig. 14. Cumulative values for inlet airflow volume

\section{B. Quantitative Evaluation of Energy Saving}

Fig. 15 and Fig. 16 show the measured values and those from Cases A (ideal operating conditions), B (recreation of the difficulties), and $\mathrm{C}$ (only mechanical ventilation) for cooling load and energy consumed for each floor. A/C power consumption was calculated according to the performance curve for each floor, and total power consumption of the heat exchanger was calculated by multiplying power consumption (BEMS data) per unit time by the operation time. Measured values and those of Case B in Figs. 15 and 16 largely agree, with average errors of $3.0 \%$ in Fig. 15 and $2.4 \%$ in Fig. 16. Taking the measured values and those of Case $\mathrm{C}$ in Fig. 16, power consumption for $\mathrm{A} / \mathrm{C}$ was reduced by about $20 \%$ on each floor, and predicted energy savings for the system was about $22.3 \%$ on average. Resolving the difficulties experienced in Case A should increase energy savings to an average $28.1 \%$.

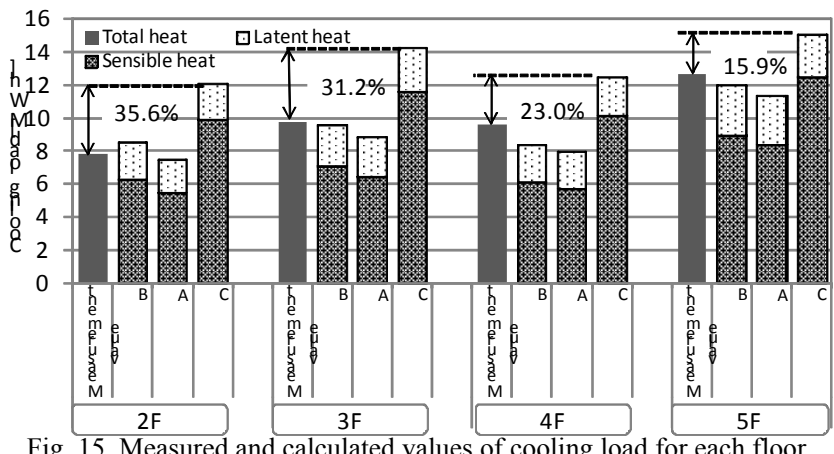

Fig. 15. Measured and calculated values of cooling load for each floor

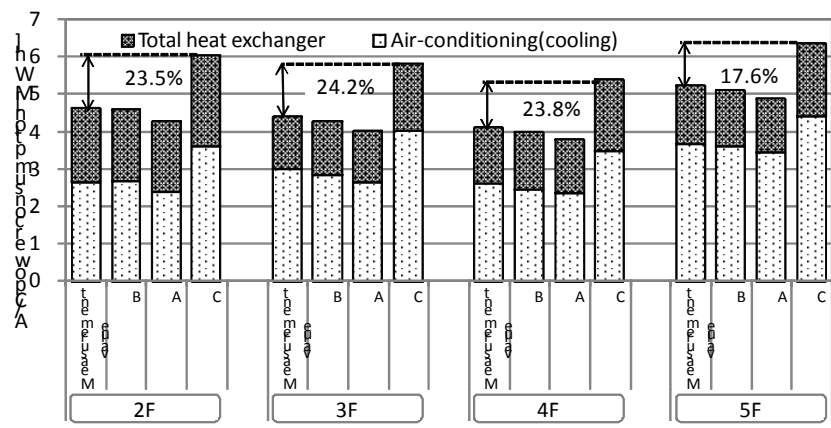

Fig. 16. Measured and calculated values of $\mathrm{A} / \mathrm{C}$ power consumption

\section{CONCLUSION}

This paper reports results of the energy-saving effect of a hybrid A/C system with flow control inlets and outlets during operation phase in springtime based on field measurements and numerical simulations. A numerical model of the natural ventilation rate for a building with flow control inlets and outlets was proposed in this study by means of a thermal and air flow network analysis. The prediction accuracy of this model was also verified by performing a comparison with field measurements of a hybrid $\mathrm{A} / \mathrm{C}$ system in an existing office building. The calculation errors of cumulative values for natural ventilation time, inlet airflow volume, and $\mathrm{A} / \mathrm{C}$ power consumption were less than $10 \%$ on average respectively, and so predictions by the proposed numerical model had sufficient accuracy. Power consumption for A/C was reduced by about $20 \%$ on each floor by introducing natural ventilation, and predicted energy savings for the system was about $22.3 \%$ on average.

\section{REFERENCES}

[1] T. Chikamoto, S. Murakami, S. Kato, N. Kitamura, W. Ho, and T. Kim, "Study on Hybrid Air Conditioning System using Natural Ventilation in Office Space : Part 1- Purpose and Outline of the Study," Summaries of Technical Papers of Annual Meeting Architectural institute of Japan. Environmental Engineering II, 1997, pp.597-598.

[2] H. Chang, S. Kato, S. Murakami, T. Chikamoto, and T. Kim, "Study on hybrid air-conditioning based on natural and mechanical ventilation in office building: Part 1-Effects of outdoor air on task \& ambient type hybrid air-conditioning system and energy conservation," Transactions of the Society of Heatin, Air-Conditioning and Sanitary Engineers of Japan, No. 83, pp.81-90, Oct.2001

[3] K. Mizuide, H. Ishino, K. Kohri, A. Nakaga, T. Nagai, K. Otaka, and K. Oohara, "A study on performance evaluation and control method design about a hybrid air conditioning system with a combination of natural ventilation and ceiling fans," Journal of Environmental Engineering (Transactions of AIJ), no.604, pp.69-76, June 2006. 
[4] Japan Meteorological Agency, Weather, Climate \& Earthquake Information. [Online]. Available: http://www.jma.go.jp/jma/menu/report.html

[5] H. Okuyama, "Thermal and Airflow Network Simulation Program NETS," in Proceedings of Sixth International IBPSA Conference (Building Simulation 99), 1999, pp.1237-1244.

[6] R. Yasunaga, Y. Ashitani, Y. Shiraishi, Y. Uchikawa, and Y. Nakamura, "Hybrid air-conditioning system using natural ventilation in an office building with flow control inlets and outlets: Part 1Evaluation of natural ventilation rate by means of field measurement and numerical simulation in break-in stage of air-conditioning," Journal of Environmental Engineering (Transactions of AIJ), no.678, pp.681-688, Aug. 2012.
[7] T. Tachikawa and H. Nishi, "Estimation method of the number of people in a room by using environmental sensors," Journal of Environmental Engineering (Transactions of AIJ), no.650 pp.355-362, Apr. 2010.

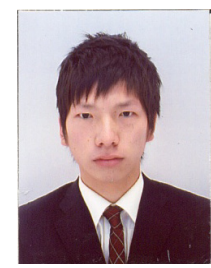

Tomoya Sakamoto is a graduate student of The University of Kitakyushu, Japan. 